\title{
Characterizing the Gonadosomatic Index and Its Relationship with Age in Greater Cane Rat (Thryonomys swinderianus, Temminck)
}

\author{
Adebayo, A.0. ${ }^{1,2}$, Oke, B.0. ${ }^{2}$, Akinloye, A. $\mathrm{K}^{1}$ \\ 1. Department of Veterinary Anatomy, University of Agriculture, Abeokuta. \\ 2. Department of Veterinary Anatomy, University of Ibadan, Ibadan.
}

With 4 figures

received in November 2009 and accepted for publication December 2009

\begin{abstract}
This work investigated the gonadosomatic index $(\mathrm{Gl})$ by weight and by volume and its relationship with age in the greater cane rat raised in captivity at Igbesa, a suburb of Agbara Industrial layout in Ogun state, Nigeria. The actual weights and volumes of the testes of 18 sexually matured male animals, obtained after sacrificing the rats, were used to evaluate the gonadosomatic indices. The results obtained showed that the cane rat has low investment in its spermatogenic tissue and spermatozoa having $\mathrm{Gl}$ by weight and by volume of $0.053 \%$ and $0.059 \%$ respectively, compared to other rodents like mouse $(0.4 \%$ in Mus pahari, $3 \%$ in Mus spicilegus), $0.72 \%$ in gerbils, $0.3-9.1$ in lemur and $0.88 \%$ in African giant rat. Also, it was observed that low relationship existed between testicular size $\left(r^{2}=0.23\right.$, $p<0.05)$ and the $G I\left(r^{2}=0.41, p<0.05\right)$ in sexually matured males. The result showed that as the animal ages even with increased body weight its GI declines. These observations can serve as aid for farmers involved in captive rearing of this animal and contribute to the knowledge of the reproductive biology of the male cane rat.
\end{abstract}

\section{Key words}

Captive rearing, gonadosomatic index, greater cane rat, spermatogenesis.

\section{Introduction:}

The greater cane rat (Thryonomys swinderianus, Temminck) is a prolific wild rodent, of the order hystricomorpha that is vigorously hunted and exploited in most areas, particularly in West Africa South of Sahara (Asibey, 1974; Ajayi and Tewe, 1980). It is currently undergoing domestication and captive rearing in this region and the recent trend in its farming is towards increased stock levels and intensification of production practices (Adu et al, 2005). Thus, a good understanding of the reproductive biology particularly the anatomy of the male reproductive system is very vital (Segatelli, 2004). According to Setchell (1992), a number of factors that can influence reproduction are changed by the simple act of holding wild animal in captivity. One of such factors is the gonadosomatic index of the male reproductive system.

The gonadosomatic index which is either the testicular volume per body 
weight or testicular weight per body weight is species specific and varies with age and breeding season even within the same species (Pochron et al, 2002). Gomendio et al., (2006) reported that this index predicts the rates of sperm production as well as the sperm function in a given species. Since the rate of spermatogenesis is determined by gonadal mass, males tend to grow relatively large testicle in species where the ejaculates of different males cooccur and compete for the fertilization of a set of ova in the female reproductive tract at the time of ovulation. Evidence that sperm competition favours evolution of larger testes relative to body mass (gonadosomatic index) comes from multiple comparative and experimental evolution studies across a number of taxa (Birkhead and Møller, 1998; Bjork and Pitnick, 2006). According to Pizzari (2006), rodents particularly murids are an appropriate eutherian taxon for the study of sperm competition because the high inter-specific variation in male gonadosomatic index values indicates different levels of sperm competition across species. Such variation has also been observed in the lemurs (Glander et al, 1992; Pochron et al., 2002)

Therefore, this study seeks to characterize the gonadosomatic index, to determine whether the index varies with age and to explain, from anatomical perspective, the rationale behind the breeding-up composition in the greater cane rat raised in captivity.

\section{Materials and method:}

\section{Subjects:}

A total of eighteen (18) adult male greater cane rats, bred (with known dates of birth) and raised in captivity, were used in the study. They age be-

J. Vet. Anat. tween 13 and 41 months and weighed between $1.4 \mathrm{~kg} \quad \square \quad 4.01 \mathrm{~kg} \quad(1400$ $4010 \mathrm{~g})$. All the animals had brownish perineal staining which was taken as index of sexual maturity in male cane rats as reported by Adu and Yeboah (2003). They were maintained on Elephant grass stems and water was given ad libitum

\section{Sample collection:}

Each animal was weighed alive and sacrificed after anaesthesia with chloroform in a close container. The abdominal part was then dissected open through a mid ventral abdominal incision. The ischiatic arch was completely removed to expose the reproductive organs. The testis was collected and weighed (using the microwa analytical balance) after dissecting out the epididymal duct and the gubernacular testis.

Calculating the gonadosomatic indices (GI) and statistical analysis:

The volume of the testis was obtained by water displacement method. The volumes of the left and right testicles were averaged and gonadosomatic index by volume was calculated by dividing average testicular volume $\left(\mathrm{cm}^{3}\right)$ by the body weight (g). The gonadosomatic index by weight was calculated by dividing the average of the weights of the right and left testicles by the body weight $(\mathrm{g})$. The data were analysed with regression and correlation analysis using Microsoft Excel ${ }^{\circledR}$ data analysis tool.

\section{Results and Discussion:}

Generally, the testis of the greater cane rat was milky $\square$ white in colour and had an elongated ovoid shape with blunt cranial and caudal ends. The caudal pole was broader than the cranial pole and had the gubernacular testis on it which extended into the scrotal sac (Fig. 1). 
From this study, the gonadosomatic index of the greater cane rat was $0.053 \%$ by volume and $0.059 \%$ by weight. This is small compared to what obtains in mouse; $0.4 \%$ in Mus pahari, $3 \%$ in Mus spicilegus (Gomendio, et al. 2006), $0.72 \%$ in gerbils (Segatelli, et al, 2004), 0.3 - 9.1 in lemur (Pochron, 2002) and $0.88 \%$ in African giant rat (Oke, 1988). This implies that the cane rat has low investment in its spermatogenic tissues and spermatozoa. It also showed that the animal does not show variation in gonadosomatic index in captivity. Harvey and Harcourt (1984) observed that, males may vary their investment in sperm and spermatogenic tissue according to need and the probability of gaining access to estrous females. Males with high confidence of gaining sole access to estrous females may invest as little as necessary to ensure fertilization while males likely to mate with promiscuous females may invest more in spermatogenic tissue and spermatozoa. The management practice of raising the greater cane rat in family of five comprising a male with four females and the intense male-male aggression noticed in this animal can easily be explained from this anatomical standpoint. The male cane rat in captivity has sole access to the females.

Seasonality of breeding has been reported to be a major factor in the variation of the gonadosomatic index in the wild (Pochron, 2002). According to Alarape (2002), cane rat breeds throughout the year in captivity and so the absence of variation in gonadosomatic index is expected in captive cane rat. Although seasonal breeding was observed in the wild cane rat by Onadeko (1996) the likelihood of variation in the gonadosomatic index is yet to be proven.

Figure 2 illustrates the relationship between the gonadosomatic index (GI) by weight and by volume. A linear relationship between $\mathrm{Gl}$ by weight and $\mathrm{Gl}$ by volume yields the equation: $\mathrm{Gl}$ (by weight) $=1.0154 \mathrm{Gl}$ (by vol.) $\square 0.0018$ with coefficient of correlation $\left(r^{2}\right)$ of 0.97 and $p$-value $<0.001$. In the work of Pochron, et. al, (2002) on lemur (Milne Edwards $\square$ sifaka), the GI (by vol.) was estimated from live animals by measuring the length (I) and the width (w) of the testes. The testicular volume was then calculated from the formula $4 / 3$ pi (I) $\left(w^{2}\right)$ and the $\mathrm{Gl}$ (by vol.) determined by dividing the testicular volume by body weight. This implies that, from the linear relationship, the GI (by weight) in the cane rat can easily be evaluated without necessarily sacrificing the animal. Most importantly, since the rate of spermatogenesis is determined by gonadal mass (Gomendio et al, 2006), the evaluation of $\mathrm{Gl}$ (by weight) without losing the animal may aid farmers involved in captive rearing of the greater cane rat in selecting males for breeding.

Figure 3 and 4 shows the weak negative correlation that existed between the age and $\mathrm{Gl}$ (by weight) $\left(r^{2}=0.41, p\right.$ $<0.05$ ) as well as between age and average testicular weight $\left(r^{2}=0.23, p<\right.$ $0.05)$. Also the variation of $\mathrm{Gl}$ with age yielded a non linear relationship (Fig. 4) with the equation: GI (by weight) \% = $0.1752 \mathrm{e}-0.0614$ (age). This shows that at sexual maturity in the greater cane rat, the relationship between testicular size and age is low and as the animal ages the testicular size as well as the $\mathrm{Gl}$ decreases. This finding lends credence to what has been observed in lemur (Pochron, et. al, 2002).

From the diagrams (Fig. 3 and 4) the bulk of the point are scattered between area covered from 15-25 months indicating that animals within this age bracket might be the best for breeding programme judging from testicular size 
and the gonadosomatic index. These findings confirm the observation of Onadeko (1996) that old male cane rat weighing as much as $4.46 \mathrm{~kg}$ did not secrete any semen despite satisfactory reaction to electro-ejaculation.

In conclusion, this work has provided information about the gonadosomatic index in the greater cane rat which can aid in the captive rearing of this animal as well as contribute to the knowledge of the reproductive biology of the male cane rat.

\section{References:}

Adu, E. K and Yeboah, S. (2003): On the use of perineal stain as an index of sexual maturity and breeding condition in the male greater cane rat (Thryonomys swinderianus, Temminck). Tropical Animal Health and Production, 35(5), 433-439

Adu, E. K, Otsyina, R.H and

Agyei A. D (2005): The efficacy of different dose levels of albendazole for reducing fecal worm egg count in naturally infected captive grass cutter (Thryonomys swinderianus, Temminck). Livestock research and rural development. 17 (11) 1-6

Ajayi, S.S and Tewe, O.O

(1980): Food preferences and carcass composition of the Grasscutter (Thryonomys swinderianus) in captivity. African Journal of Ecology 18 (2 \& 3) $133 \square 140$.

Alarape, A.A (2002): Cane rat (Thryonomys swinderia-nus) production $\square$ An effective source of income for the household. OBECHE Vol. 24. Pp $2 \square 6$.

Asibey, E.O.A. (1974): Wildlife as source of protein in Africa: South of the Sahara. Biol Conserv 6(1): $32 \square 39$.

Birkhead, T. R., Møller, A. P. (1998):Sperm Competition and Sexual Selection (Academic, San Diego).

Bjork, A. and Pitnick, S. (2006): Intensity of sexual selection along the anisogamy isogamy continuum. Nature 441:742 745.

Glander, K. E., Wright, P. C., Daniels, P. S. (1992):

Morphometrics and testicle size of rain forest lemur species from south-eastern Madagas-

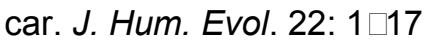

Gomendio, M., Martin-Coello, J., Crespo, C., Magaña, C. and Roldan, E.R.S (2006): Sperm competition enhances functionnal capacity of mammalian spermatozoa. Proceeding of National Academy of Science. USA 103:15113 $\square 15117$

Harvey, P. H., and Harcourt, A.

H. (1984): Sperm competition, testes size, and breeding systems in primates. In Smith, R. L. (ed.), Sperm Competition and the Evolution of Animal Mating Systems, Academic Press, San Diego, pp. $589 \square$ 600.

Oke, B.O. (1988): Some aspects of the reproductive biology of the male African giant rat (Cricetomys gambianus, Waterhouse). Ph.D. Thesis, University of Ibadan.

Onadeko, S.A. (1996): The reproductive ecology of the Grasscutter (Thryonomys swinderianus, Temminck) in captivity. Ph.D Thesis, University of Ibadan.

Pizzari, T.( 2006): Of mice and 
sperm. Proceeding of National Academy of Science USA 103:15113

Pochron, S. T.,Wright, P.

C.,Schaentzler, E., Ippolito, M., Rakotonirina, G., Ratsimbazafy, R and Rakotosoa, R. (2002): Effect of Season and Age on the Gonado-somatic Index of Milne Edwards $\square$ Sifakas (Propithecus diadema edwardsi) in Ranomafana National Park, Madagascar. International Journal of Primatology, Vol. 23, (2) 355-364
Segatelli, T. M., França, L. R., Pinheiro, P. F. F., Alemi-da, C. C. D., Martinez, M. and Martinez, F. E. (2004): Spermatogenic Cycle Length and Spermatogenic Efficiency in the Gerbil (Meriones unguiculatus). Journal of Andrology, Vol. 25, No. 6. Pp. $1 \square 21$.

Setchell, B.P. (1992):

Domestication and Reproduction. Animal Reproduction science. 28. 195-202.

Table 1: The mean and standard deviation of the Age, Gonadosomatic index (by volume) and Gonadosomatic index (by weight) of 18 male cane rats.

\begin{tabular}{|l|c|c|c|}
\hline & Age (months) & GI (by volume) & Gl (by weight) \\
\hline Mean & 20 & 0.053 & 0.059 \\
\hline $\begin{array}{l}\text { Standard dev- } \\
\text { iation }\end{array}$ & \pm 5.35 & \pm 0.022 & \pm 0.017 \\
\hline
\end{tabular}

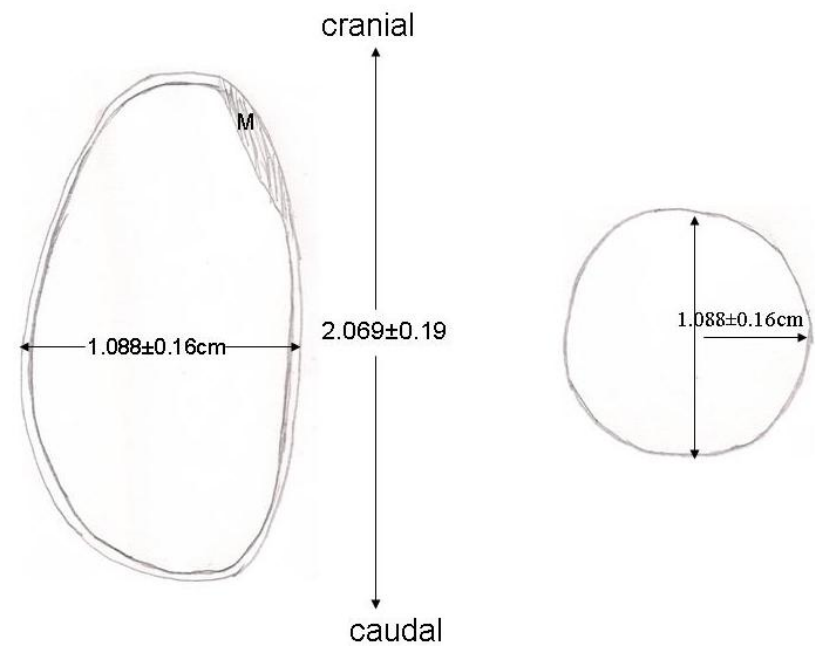

Fig. (1): shows the schematic diagram of the shape and the linear dimensions of the testis of the greater cane rat (Thryonomys swinderianus, Temminck). Note the mediastinum testis (M) on the longitudinal section of the testis. The right diagram shows the transverse section. The diagram is not drawn to scale 


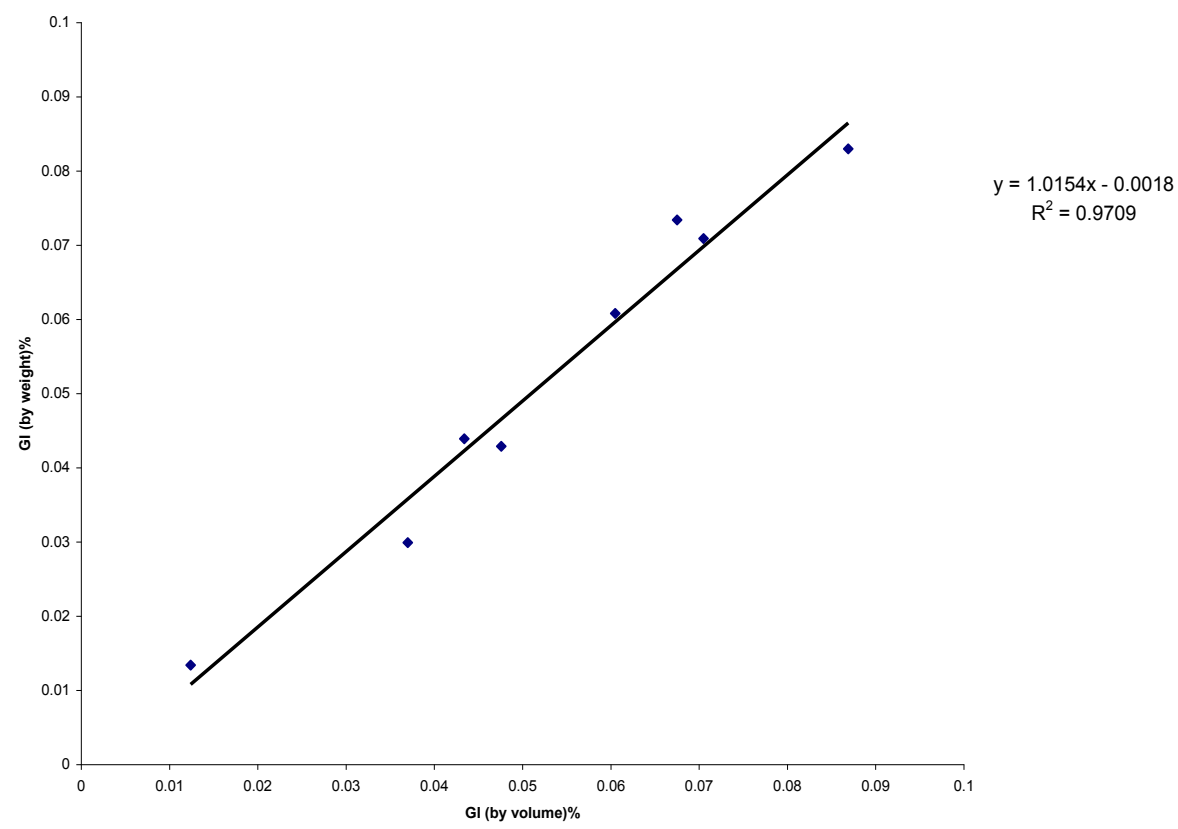

Fig. (2): shows the scattered diagram illustrating the linear positive relationship between of the GI (by weight) and GI (by volume) in the greater cane rat raised in captivity. The coefficient of correlation $\left(r^{2}\right)$ of the relationship is 0.97 with $p<0.05$.

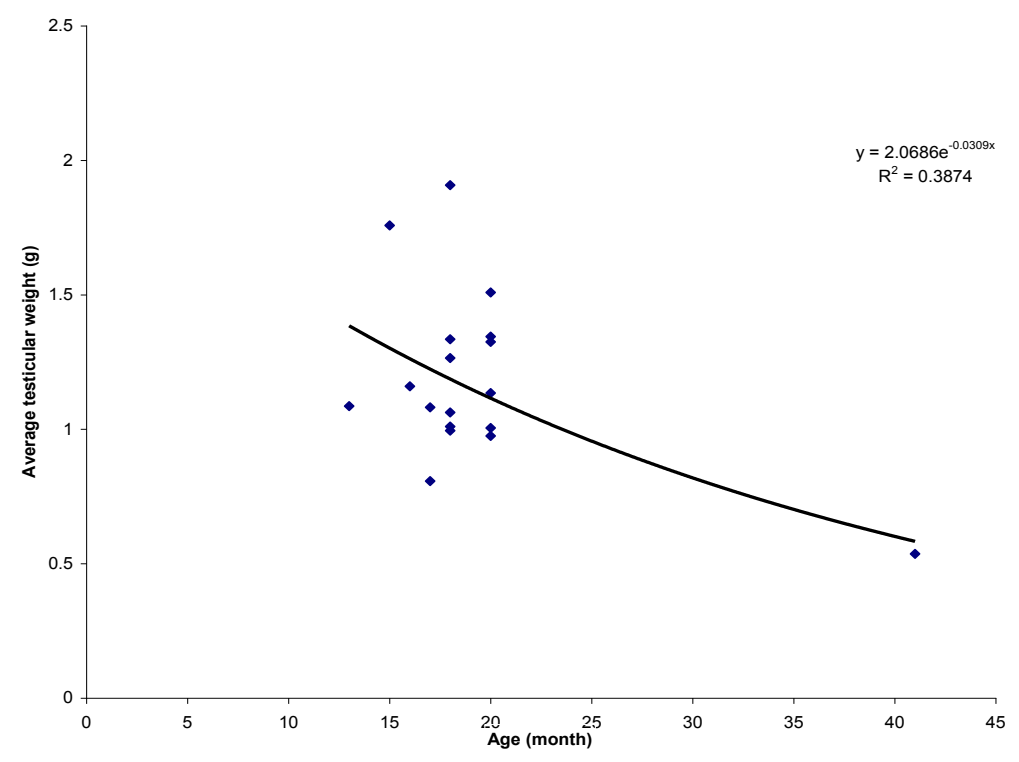

Fig. (3): shows the scattered diagram illustrating the non linear negative relationship between the Age (month) and average testicular weight $(\mathrm{g})$ of sexually matured captive male cane rat. 


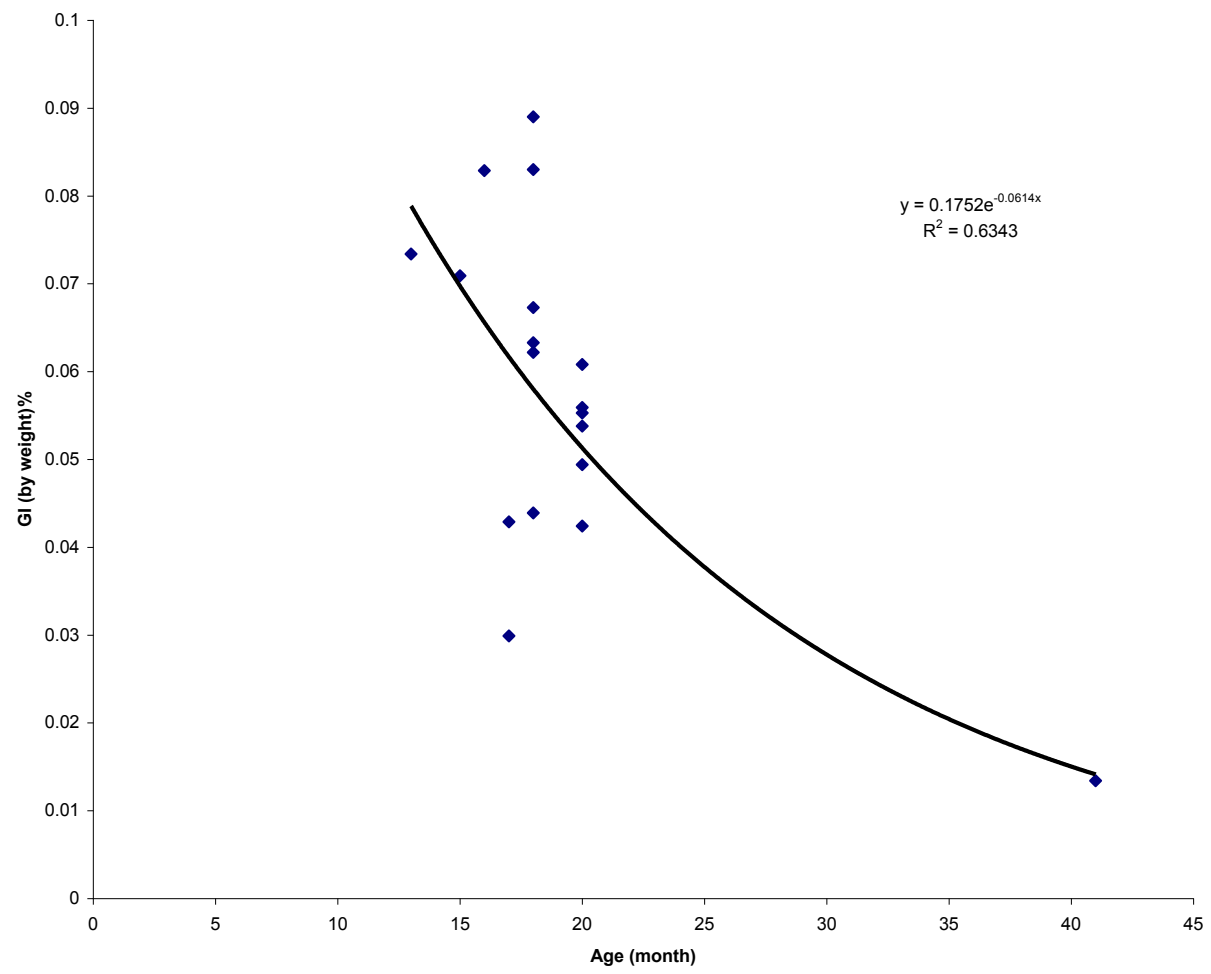

Fig. (4): shows the scattered diagram that illustrates the non linear negative relationship between Age (month) and Gl (by weight) of sexually matured captive male cane rat. 